\title{
Shared Arguments in Modern Standard Arabic
}

\author{
Yasir Hameed Alotaibi ${ }^{1}$ \\ ${ }^{1}$ Prince Sattam bin Abdulaziz University, Al Kharj, Saudi Arabia \\ Correspondence: Yasir Hameed Alotaibi, Prince Sattam bin Abdulaziz University, Al Kharj, Saudi Arabia. E-mail: \\ yasirho@hotmail.co.uk
}

Received: August 1, 2017 Accepted: September 22, 2017 Online Published: October 25, 2017

doi:10.5539/ijel.v8n1p164 URL: https://doi.org/10.5539/ijel.v8n1p164

\begin{abstract}
This paper discusses shared arguments in coordinate structures in Modern Standard Arabic (MSA). It assumes that a shared argument between two conjuncts can be a subject or an object. The paper uses the lexical-functional grammar (LFG) framework for analyzing this kind of structure. In LFG, the two possible analyses for similar structures involve analyzing the shared argument as bearing two functions in the two conjuncts. The first analysis is the split analysis, where the shared argument is zipped to both conjuncts by assuming that the verb phrases in both conjuncts are split. The second analysis is function spreading, in which the function of the shared argument is spread from one conjunct to another. This paper argues that the previous analyses in LFG have faced some problems in accounting for this phenomenon in MSA. To solve these problems, this paper contributes a new analysis for shared arguments that involves analyzing the missing argument, whether it is a subject or an object, as a null argument.
\end{abstract}

Keywords: nonconstituent coordination, function spreading, split, lexical-functional grammar, null argument

\section{Introduction}

This paper discusses nonconstituent coordination or shared arguments in MSA and uses an LFG approach to account for this phenomenon. The term shared arguments is used to refer to two types of sharing that occur in MSA and other languages. In a coordinate structure, the two conjuncts may share the same subject or object. The following examples from MSA show the two types of sharing (Note 1):

(1)
a. al-țāib-u $\underline{\text { d}} \bar{a} k a r a$
al-dars- $a$
wa nă̆aha
fĩ DEF-student study.PFV.3SGM DEF-lesson-ACC and succeed.PFV-3SGM in al-Pihtibār-i. DEF-exam-GEN

'The student studied the lesson and (he) succeeded in the exam'

b. qābal-tu wa kallama fāris-un Pạ̣mad-a. meet.PFV-1SG and talk.PFV.3SGM Faris-NOM Ahmad-ACC 'I met (Ahmad) and Faris talked to Ahmad'

In example (1a), two conjuncts share the same subject; the verb $\underline{\text { dakara }}$ "studied" in the first conjunct and the verb nağaha "succeeded" in the second conjunct share the same subject, which is al-țalib-u "the student". By contrast, the two conjuncts in example (1b) share the proper noun Ahmad, which functions as an object for both verbs in this coordinate structure. The latter phenomenon, which is called right node raising (RNR) and found in many languages, has attracted some attention in the literature. This paper discusses both phenomena and provides an appropriate analysis within the LFG framework (Note that this paper is assuming that there is no a pronoun, functioning as a subject in example (1a)).

The paper is organized as follows: Section 2 provides data from MSA; section 2.1 explains the data on RNR in 
MSA, and 2.2 shows the sharing in subject function. Section 3 discusses the previous analyses in LFG, and it begins by providing a brief overview of LFG and the analysis of coordinate structure in this framework. The discussion of previous LFG analyses of a similar phenomenon is presented in 3.1, where split analysis is explained, and in 3.2, where function spreading is discussed. In this section, this paper demonstrates that both analyses are unable to account for all examples in MSA. Therefore, section 4 introduces a new analysis in LFG that can account for all examples in MSA. In this analysis, the missing arguments are analyzed as null arguments.

\section{Data}

This section discusses two kinds of phenomena that are related to one another in MSA, as demonstrated in the analysis in this paper. The first phenomenon is RNR, where a shared element between two conjuncts in a coordinate structure appears in the second conjunct and functions as an object. The second phenomenon also has a shared element between two conjuncts in a coordinate structure, but the shared element here functions as a subject rather than an object. Both phenomena are regarded as a kind of a nonconstituent coordination in this paper (Note 2).

\subsection{Right Node Raising}

This part of the paper discusses RNR and shows its properties in MSA, such as the position of the missing element, the ability to share a nonconstituent element, the types of conjunctions and the types of predicates that are used in this structure. The term RNR pivot is used in this paper to refer to an element that is shared by conjuncts in an RNR structure.

The position of the RNR pivot is usually the same in a variety of languages. In particular, the position of RNR pivot is at the right of a coordinate structure in many languages. Ross (1967), Postal (1974), Wilder (1999), Hartmann (2000), Sabbagh (2007), Ha (2008), Shabani (2015) and others state that the RNR pivot must be located at the right of this structure. The following examples illustrate the position of the RNR pivot in the English language:

(2)

a. [David fixed ...... ] and [Mary watched the television].

b. *[David fixed ..... ] and [Mary watched the television] on Friday.

In both examples above, the argument the television is shared by the two predicates fixed and watched in the two conjuncts. In example (2a), this element is spelled out at the rightmost position of the second conjunct; therefore, this sentence is grammatical. By contrast, the shared element is spelled out in the second conjunct but is not at the rightmost position, and hence, the sentence is ungrammatical. Furthermore, the location of the deleted element in the first conjunct must be at the rightmost position, according to Duman and van Riemsdijk $(2003,7)$, who uses the following ungrammatical example as evidence that the deleted element must be at the rightmost position in the first conjunct:

(3) *[George left ...... in the drawer] and [Elaine wrote in the train theletter].

However, the case in MSA is different, as the RNR pivot can appear in other positions. The free word order of MSA allows more positions for the RNR pivot in this language. In particular, the RNR pivot can appear at the rightmost position, as shown in example (4a), and can also appear in another position in the second conjunct, as shown in example (4b). Thus, both examples below are grammatical:

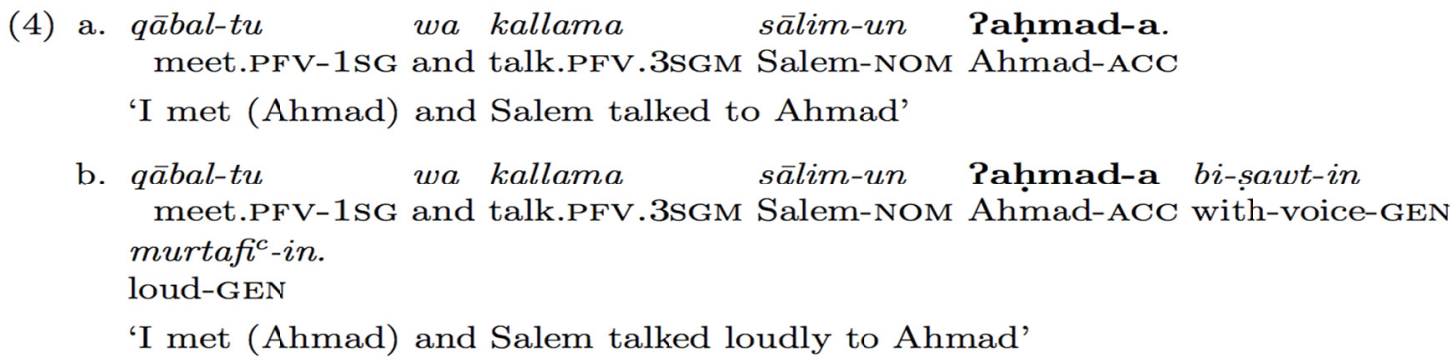

This construction in MSA involves more positions in which the RNR pivot can occur. It can occur in the first 
conjunct either before or after the predicate. The following examples illustrate the two cases: the RNR pivot occurs before the predicate qäbal "met" in the first conjunct in example (5a) and after this predicate in (5b):

(5)
a. Pahmad-a qābal-tu wa kallama Zayd-un.
Ahmad-ACC meet.PFV-1SG and talk.PFV.3SG Zayd-NOM
'I met (Ahmad) and Zayd talked to Ahmad'
b. $q \bar{a} b a l-t u$
Paḥmad-a wa kallama
Zayd-un.
meet.PFV-1SG Ahmad-ACC and talk.PFv.3sG Zayd-NOM
'I met (Ahmad) and Zayd talked to Ahmad'

\subsubsection{Constituency and Nonconstituency}

The RNR pivot can be a constituent, as in the examples above, and can be a nonconstituent, as stated by Abbott (1976) and Wyngaerd (2009), among others. The following examples illustrate nonconstituents that have undergone RNR - in English in example (6a) and in Dutch in (6b) — and both are grammatical.

(6) a. 'Leslie played, and Mary sang, some C and W songs at George's party' (Abbott, 1976, 639).

b. '[Jan heeft met het meisje dat de rode .........] en [Piet heeft met de Jan has with the girl who the red ........ and Piet has with the jongen die de witte wijn binnenbracht] gesproken'(Wyngaerd, 2009, 21). boy who the white wine in.brought talked

The case is the same in MSA, as the RNR pivot can be a constituent as illustrated in (4a), repeated in (7a), or it can be a nonconstituent, as shown in example (7b) below, in which the RNR pivot is ?ahmad-a yawma $a l-\operatorname{Prbi}^{c}{ }^{-}$? $-i$ "Ahmad on Wednesday", containing a noun phrase and an adverb phrase. Thus, the adverb yawma al-Parbi ${ }^{c}{ }^{-}$? $-i$ "the day of Wednesday" modifies both predicates in both conjuncts. Thus, the RNR pivot in this example does not form a constituent.

(7)
a. qābal-tu wa kallama sālim-un Paḥmad-a.
meet.PFV-1SG and talk.PFv.3SGM Salem-NOM Ahmad-ACC
'I met (Ahmad) and Salem talked to Ahmad'
b. $q \bar{a} b a l-t u$
wa kallama
sālim-un
Pahmad-a yawm-a al- $\operatorname{Parbi}^{\mathrm{c}} \overline{\mathbf{a}} \mathbf{P}-\mathbf{i}$.
meet.PFV-1SG and talk.PFV.3SGM Salem-NOM Ahmad-ACC day-ACC
DEF-Wednesday-GEN
'I met (Ahmad) and Salem talked to Ahmad on Wednesday'

\subsubsection{Conjunctions}

Like other languages, MSA allows RNR with a variety of conjunctions. The following examples illustrate some conjunctions in MSA with this phenomenon. In example (8a), RNR occurs with the conjunction wa "and". In example (8b), it occurs with ?aw "or". In (8c), it occurs with la kin "but": 
(8)
a. $s a m i^{c}-t u$
wa $\operatorname{sami}^{c} a$
zayd-un sālim-an.
hear.PFV-1SG and hear.PFv.3SGM Zayd-NOM Salem-ACC
'I heard (Salem) and Zayd heard Salem'

\author{
b. wabbah-tu \\ Paw lāma \\ zayd-un sālim-an. \\ reprove.PFv-1SG or blame.PFv.3SGM Zayd-NOM Salem-ACC \\ 'I reproved (Salem) or Zayd blamed Salem'
c. samic-tu lākin lāma zayd-un sālim-an.
hear.PFv-1sG but blame.PFV.3SGM Zayd-NOM Salem-ACC
'I heard (Salem) but Zayd blamed Salem'

\title{
2.1.3 Kinds of Predicates
}

In MSA, the predicates that share an element may be verbs, as illustrated in the previous examples, or kinds of predicates other than verbs; thus, similar structures in MSA can have non-verbal predicates. The active and passive participles can function as predicates in MSA (see Ryding (2005)), and in this case, two active or passive participle predicates can share the same element. The example in (9a) contains two active participles functioning as predicates and sharing an argument, which is Layla, which functions as an object of both predicates. Similarly, the two passive participles in example (9b) function as predicates and share the same argument, which is Salem.

(9)
a. hāda mukallim-un
wa hāilid-un
this.NOM talk.ACT.PTCP.3SGM-NOM and Khaled-NOM
muqābil-un
layla
gad-an.
meet.ACT.PTCP.3SGM-NOM Layla.ACC tomorrow-ACC

'They will talk (to Layla) and Khaled will meet Layla tomorrow'

b. sālim-un muqābal-un wa hālid-un

Salem-NOM meet.PASS.PTCP.3SGM-NOM and Khaled-NOM

mukallam-un min laylā.

talk.PASS.PTCP.3SGM-NOM from Layla

'Salem will be met (by Layla) and Khaled will be talked to by Layla'

Additionally, verbal nouns in MSA, which name the action of their corresponding verbs, can function as predicates (see Ryding (2005)) and share an argument in a coordinate structure as well. In example (10), the two verbal nouns hubb "love" and taqdyr "respect" share the same object, which is Khaled, and the accusative case marking at the end of this NP shows that it functions as an object of both verbal nouns.
(10) 'ağib-tu
$\min \quad h u b b-i$
zayd-in
$w a$
admire.PFV-1SGM
from love.VN-GEN-3SGM
Zayd-GEN
and
taqdyr-i-ka
hālid-an.
respect. VN-GEN-2SGM Khaled-ACC
'I admire Zayd's love (for Khaled) and your respect for Khaled' 


\subsection{Subject Function}

In all the previous examples of RNR in this paper, the shared element functions as an object. However, the shared argument in MSA can perform another function. In particular, this argument can be the subject of the two predicates in a coordinate structure. The following examples are illustrative: Khaled in example (11a) functions as the subject of both predicates in the coordinate structure. Likewise, the proper noun Ali in example (11b) functions as the subject of both predicates in this example. Importantly, this paper does not assume that the agreement of the second verbs in the following examples are pronouns functioning as subjects, which is suggested in traditional grammar of Arabic language and in other frameworks.

\section{(11)
a. hālid-un yaqra?u al-risālat-a wa yaktubu Khaled-NOM read.IPFV.3SGM DEF-letter-ACC and write.IPFV.3SGM al-radd-a. DEF-reply-ACC \\ 'Khaled reads the letter and writes the reply' \\ b. ${ }^{c} a l \bar{\imath}-u n \quad$ dākara al-dars-a wa nag்ha. \\ Ali-NOM study.PFV.3SGM DEF-lesson-ACC and succeed.PFV.3SGM 'Ali studied and succeeded'}

In this paper, both examples in (11) are considered a type of nonconstituent coordination in which the coordination is between two IPs sharing the same subject, which is pronounced in the first conjunct in this structure. This paper uses a uniform analysis to account for both sharing phenomena, namely, the RNR and the shared subject. The uniform analysis assists in accounting for some examples in MSA that show some overlap between the two phenomena. In particular, it is possible in MSA to find two predicates sharing the same argument in a coordinate structure, but each predicate requires this argument to fill a different function. The following example in (12) illustrates this situation in MSA, in which the proper noun Zayd-an is shared between the two predicates in both conjuncts but is required as a subject of the first predicate and as an object of the second predicate.

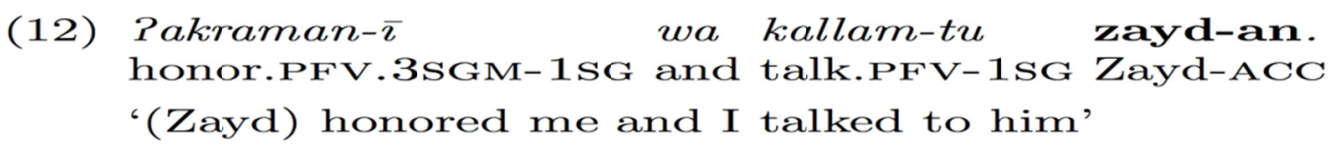

Some of the characteristics that are discussed in relation to RNR, such as the position of the missing element and the types of conjunctions, are similar when the function of the missing element is the subject. However, others, such as the nonconstituency and types of predicates, are not applicable to the subject function.

\section{Previous Analysis in LFG}

LFG has the advantage of having two levels of representation, namely, the constituent structure (c-structure) and the functional structure (f-structure). Similar to other syntactic frameworks, LFG assumes that words should be organized into constituents that are represented in trees and licensed by rules. The principle of $\mathrm{x}$-bar theory used in LFG assumes that lexical items occur as heads of phrases and that they may appear with a specifier or a complement position within the phrase. The lexical or functional category in $\mathrm{x}$-bar theory is related to a maximal or nonmaximal projection (see Jackendoff, 1977; Chomsky, 1986; Dalrymple, 2001).

The $\mathrm{f}$-structure in LFG is devoted to function information. This f-structure contains a function from attributes to values, or it can be assumed to be a set of pairs in which the first member of the pair is an attribute and the second is its value (see Kaplan \& Bresnan, 1982; Bresnan, 2001). 
Another function in LFG relates nodes in the c-structure to their corresponding f-structures; hence, nodes in the c-structure are related to specific f-structures, in which each node is related to one f-structure, while the f-structure may be related to more than onenode.

The analysis of a shared element in coordinate structures or RNR in LFG requires discussing both the c-structure and the f-structure. Before we initiate the discussion of previous analyses of nonconstituent coordination, we should begin with a brief introduction to the analysis of coordinate structures in LFG. The example in (13) below illustrates a simple case of sentential coordination in the English language. This kind of coordination is analyzed by Bresnan et al. (1985), Kaplan \& Maxwell (1988) and Dalrymple (2001) as a coordination between two IPs. The rule, the c-structure and the f-structure that are shown in (14), (15a) and (15b), respectively, are proposed for analyzing the sentence in (13) in the LFG framework. The rule in (14) indicates that this coordination is between IPs, and the annotation $\downarrow \in \uparrow$ beneath the IPs indicates that the f-structures that correspond to the IPs, which are named $\mathrm{j}$ and $\mathrm{y}$ in the $\mathrm{f}$-structure in (15b), are members of a set in the main $\mathrm{f}$-structure. The advantage of using a set in this analysis is that it allows a coordinate structure to have properties that are nondistributive, meaning that the conjuncts in a coordinate structure do not have these properties individually. In other words, this analysis allows the whole coordinate structure to have different properties from the individual conjuncts. For example, the tense feature in the f-structure $j$ or $y$ is a distributive feature because it is distributed to a specific conjunct. In contrast, if any feature is added beneath the feature CONJ "and", it will be nondistributive, as it is a property of the whole coordinate structure and is not distributed to any conjunct. The symbol + in the rule below means that more than one IP can occur before the conjunction, and this is optional in the English language.

(13) David failed and Mary succeeded.

$$
\mathrm{IP} \longrightarrow \begin{array}{ccc}
\mathrm{IP}+ & \text { Conj } & \text { IP } \\
\downarrow \epsilon \quad \uparrow & \uparrow=\downarrow & \downarrow \epsilon
\end{array}
$$

The c-structure in (15a) corresponds to the f-structure in (15b). The annotation $\uparrow=\downarrow$ beneath some daughters in the c-structure indicates that they occur in the same f-structure as their mother, while the annotation ( $\uparrow$ SUBJ) $=\downarrow$, which appears beneath both NPs in both conjuncts, indicates that both NPs occur in the embedded f-structures, named SUBJ, and they fill the subject function required by both predicates. As shown in the f-structure in (15b), both IPs, which represent both conjuncts, appear in f-structures inside the set. Each f-structure inside the set has an attribute called PRED whose value shows the requirement of the predicate. Both predicates in both conjuncts require a subject only, and this is represented in both f-structures.

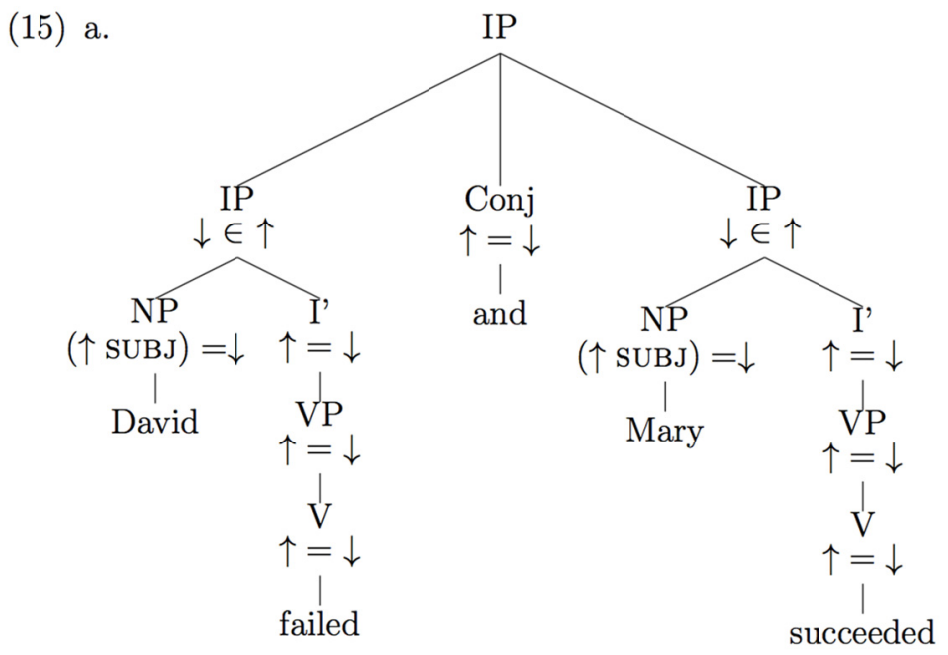




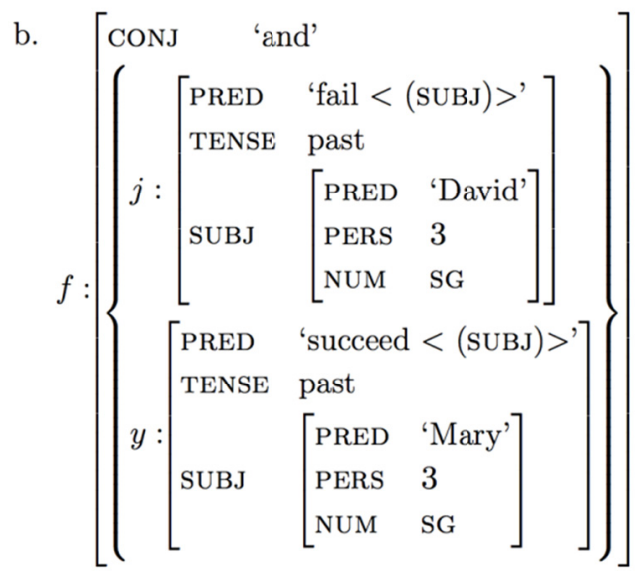

The remainder of this section discusses the analysis of shared arguments in the LFG framework. The section reviews two suggested analyses for RNR in LFG. The first analysis was proposed by Maxwell and Manning (1996) for nonconstituent coordination in general, and in this analysis, the verb phrases (VPs) in both conjuncts are split. In RNR, the shared element will be zipped to each conjunct. The second analysis in LFG is function spreading, in which the shared element in one conjunct can be spread over the whole coordinate structure. This paper argues against both analyses in LFG, claiming that the two analyses are unable to account for all examples of shared arguments in MSA.

\subsection{Split Analysis}

In the LFG framework, Maxwell \& Manning (1996) propose a theory that is able to account for nonconstituent coordination in some languages. Maxwell \& Manning (1996) argue that the example in (16) is acceptable because the object potatoes is a valid object for the verb likes in the first conjunct and also a valid object for the verb dislike in the second conjunct. This analysis can be performed by allowing both VPs in both conjuncts to be split. In this case, rules of coordination refer to partial constituents. This structure in this analysis contains two VPs, and each is split into two VPs: the first one contains the verb, and the second, which is shared between both conjuncts, contains the object. This assumption is allowed by the phrase structure rules in (17), (18) and (19). In this proposal, the X-VP, which contains the object potatoes, can be zipped to both conjuncts, which contain two incomplete VPs.

(16) “John likes and Bill dislikes potatoes” (Maxwell \& Manning, 1996, p. 7).

\begin{tabular}{|c|c|}
\hline (17) $\mathrm{VP} \longrightarrow$ & $\begin{array}{l}\text { VP-x } \\
\downarrow \in \uparrow\end{array}$ \\
\hline (18) VP-x $\longrightarrow$ & $\begin{array}{c}\mathrm{V} \\
\downarrow \in \uparrow\end{array}$ \\
\hline (19) $\mathrm{x}-\mathrm{VP} \longrightarrow$ & $\begin{array}{c}\mathrm{NP} \\
(\uparrow \mathrm{OBJ})=\downarrow\end{array}$ \\
\hline
\end{tabular}

In rules (17) and (18), the annotation $\downarrow \in \uparrow$ indicates that the f-structures that correspond to the VP nodes in (17) or the V node in (18) are members of a set in the f-structure of the mother node. The annotation ( $\uparrow$ OBJ) $=\downarrow$ implies that the NP, which is the shared argument, functions as an object; thus, the f-structure of this node is a value of an attribute, labeled OBJ in the the f-structure of the mother node. The rules above allow a sentence such as (16), repeated in (20a) with the c-structure in (20b). 
(20) a. 'John likes and Bill dislikes potatoes'(Maxwell and Manning, 1996, 7).

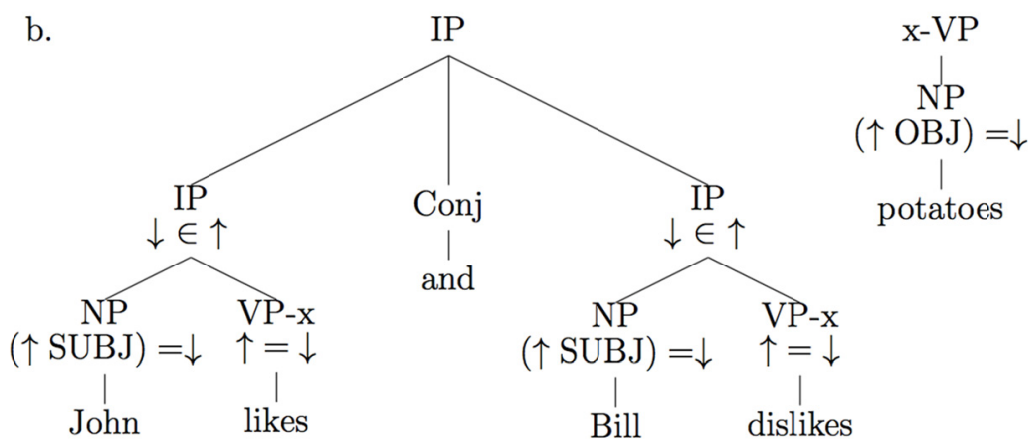

The RNR pivot, which contains the NP potatoes in example (20a), is obviously outside the coordinate structure and should be zipped to both conjuncts to constitute a complete sentence in each conjunct.

However, some problems in this analysis render it unable to account for some MSA examples. In MSA, the RNR pivot may be unsuitable for both predicates in a coordinate structure. For example, the coordinate structure in example (21) contains two verbs that require different complements. In the first conjunct, the verb dahala "entered" requires an NP as a complement, but the verb harağa "left" in the second conjunct requires an oblique as a complement. The prepositional phrase (PP) mina al-manzil-i "from the house" satisfies the requirement of the second predicate, which is harağa "left". This example shows that the analysis of Maxwell and Manning (1996) fails to account for all examples of this phenomenon in MSA. If we assume that the NP al-manzil- $i$ "the house" that is the object of the preposition should be outside the coordinate structure and then zipped to both predicates, this assumption causes a problem in that the predicate in the first conjunct requires an object that carries an accusative case marker; thus, the noun al-manzil-i "the house", which carries a genitive case marker, cannot fulfill the requirement of this predicate.

Another argument against this analysis comes from the fact that MSA allows the RNR pivot to occur in more than one position. In examples such as those in (5), repeated in (22), the RNR pivot occurs in the first conjunct, before and after the verb in this conjunct. The problem with both examples below is that they require the NP to occur in different positions, making the analysis more complicated.

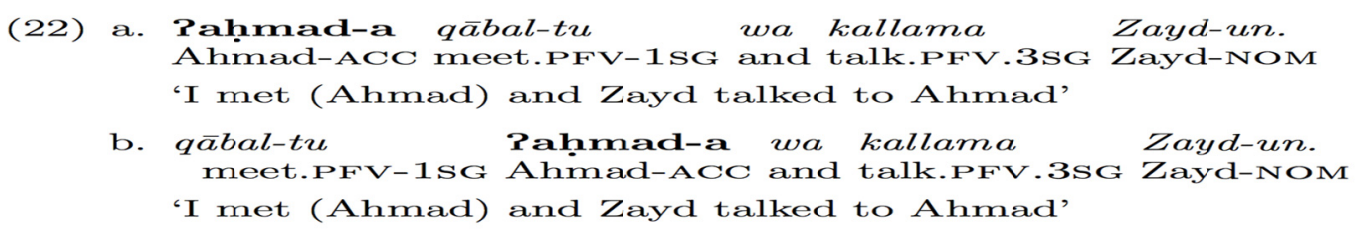

Another argument against this analysis comes from an example such as that in (12), repeated in (23) below. In this example, the predicates in the coordinate structure share an argument, which is the proper noun Zayd. However, the verb in the first conjunct requires Zayd as a subject, while the verb in the second conjunct requires it as an object. This example causes a serious problem for the analysis proposed by Maxwell and Manning (1996), as it is impossible to assume that Zayd can serve as an argument for both predicates, given that it carries accusative case marking, which is suitable for the object function; thus, this argument can function as an object for the second predicate only. 


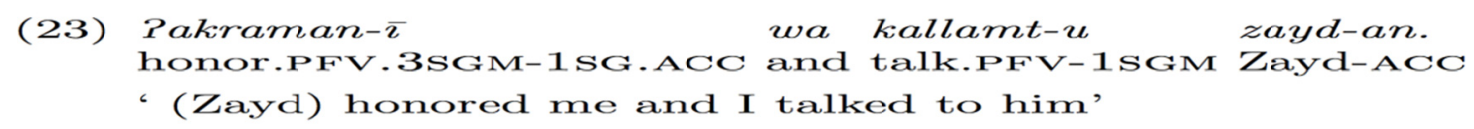

The previous examples in MSA and the ensuing problems lead us to state that the analysis proposed by Maxwell and Manning (1996) for nonconstituent coordination cannot account for this phenomenon in MSA. The following section considers another analysis for this phenomenon within the LFG framework.

\subsection{Function Spreading}

Another analysis in LFG that is used to account for nonconstituent coordination is called function spreading. This analysis allows some member of a conjunct in a coordinate structure to be spread over the whole coordinate structure. Frank (2002) uses this approach to account for the subject gap in finitelfronted coordinate structures in German. The problem in this construction is that one NP in the coordinate structure functions as a subject for all conjuncts in this construction. The following example in German, quoted from Frank (2002, p. 176), illustrates this construction:

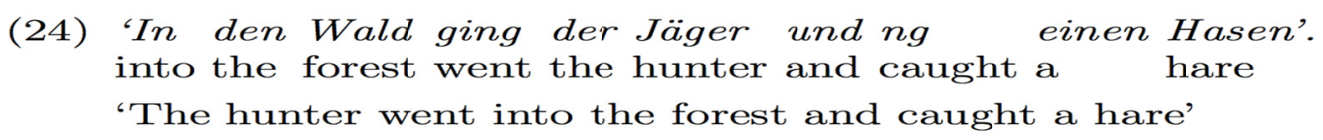

The problem in example (24) is that the second conjunct in this coordinate structure lacks a subject that is required by the verb in this conjunct. To solve this problem, Frank (2002) uses a function spreading approach that allows the subject feature to be distributed over the whole construction. Frank $(2002,188)$ proposes the following phrase structure rule for the example in (24).
(25) $\mathrm{CP}$
$\mathrm{CP}$
Conj
$\mathrm{CP}$
$\downarrow \epsilon \uparrow$
$\uparrow=\downarrow$
$\downarrow \epsilon \uparrow$

$$
(\downarrow \text { GDF })=(\uparrow \text { GDF })
$$

GDF in this rule refers to grammaticalized discourse functions, which are SUBJ, TOPIC and FOCUS. In example (24), the subject of the first conjunct is GDF, and the annotation ( $\downarrow$ GDF) $=(\uparrow$ GDF) beneath the CP ensures that the subject of the first conjunct is distributed over the whole construction; as a result, the second conjunct that lacks a subject will be complete (Note 3). The rule in (25) allows the following c-structure:

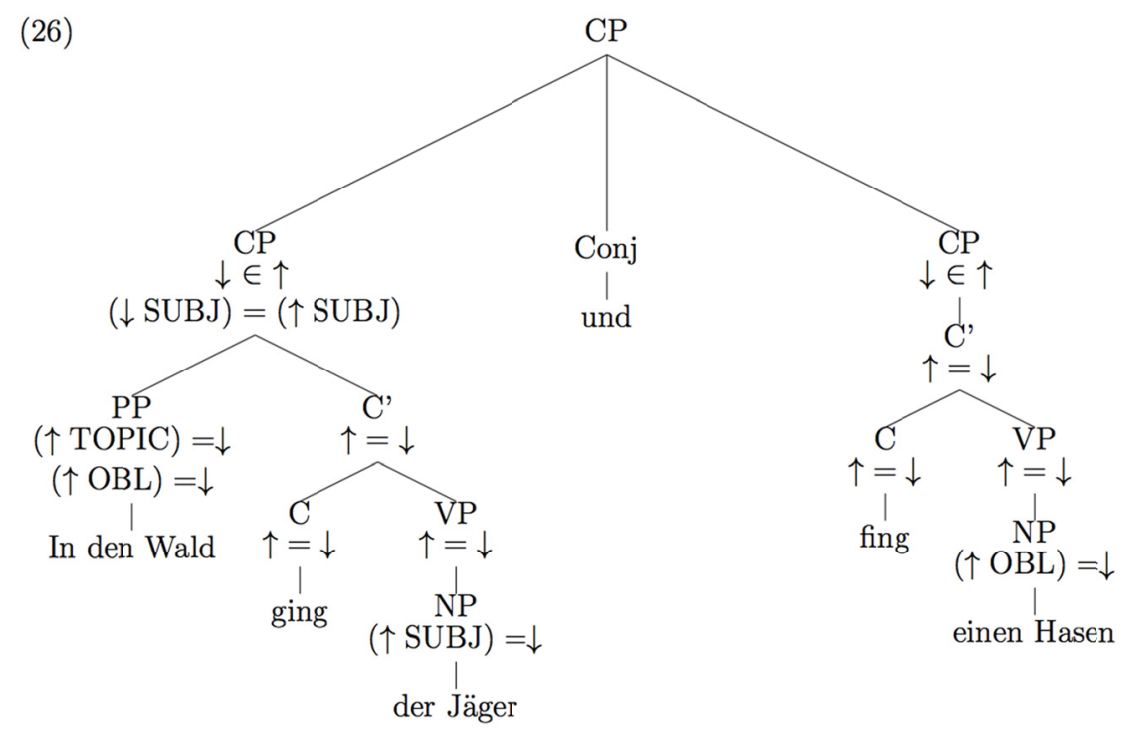


The f-structure that corresponds to this c-structure is represented in (27). The new aspect of this f-structure is that the rule in this analysis allows the two conjuncts to share the subject function. This is represented in the f-structure by number 2, which means that the SUBJ attributes in both conjuncts share the same value, which contains the NP the hunter. Given this analysis, the two predicates have all their requirements, and the f-structure is wellformed.

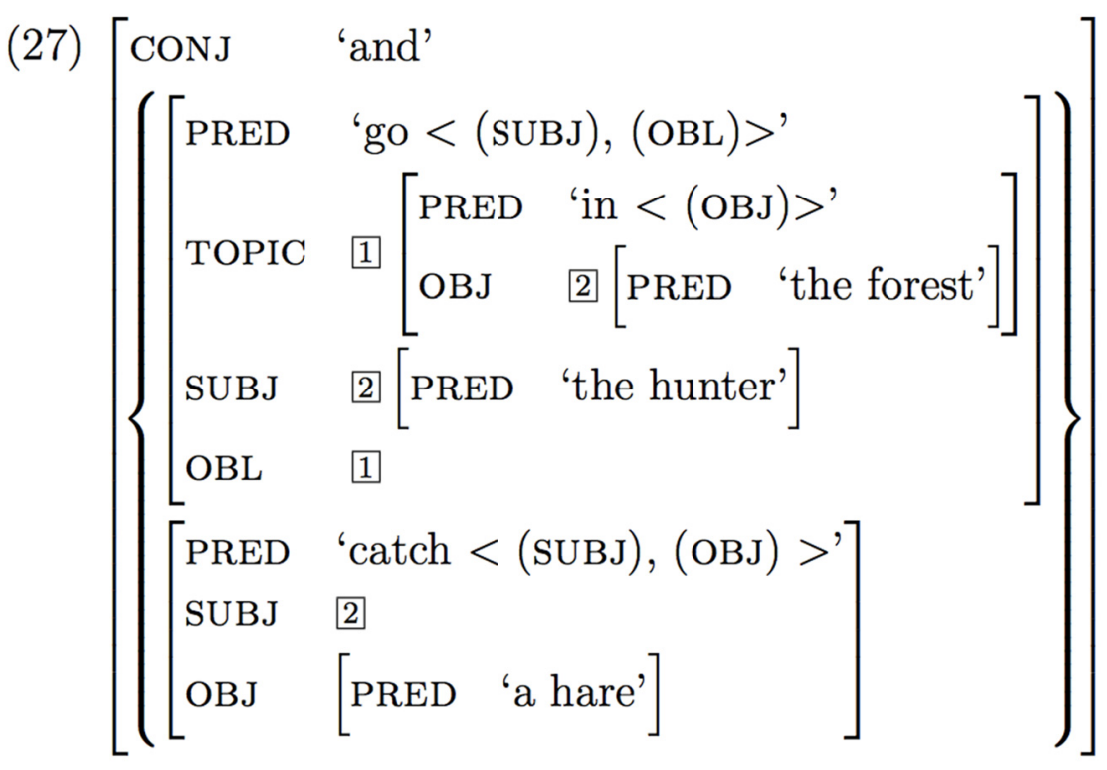

Sadler (2006) uses the same approach (function spreading) to account for a similar phenomenon in Welsh. In some coordinate structures in this language, the verb in the first conjunct is marked for tense, while the remainder of conjuncts have non-finite verbs, and the subject is shared between all the conjuncts in the construction. The following example illustrates this structure in Welsh:

$\begin{array}{lllllll}\text { (28) "Aeth } & y & \text { ffermwr at } y & \text { drws a churo arno". } \\ \text { go-PAST.3SG } & \text { the } & \text { farmer } & \text { to the door and knock on-3SM }\end{array}$

"The farmer went to the door and knocked on it" (Rouveret, 1994, p. 302)

In example (28), the verb in the first conjunct, which is aeth "went", is in the past tense, while the verb churo "knock" is not marked for any tense. However, the second conjunct is semantically interpreted as denoting the past tense. Additionally, the whole construction has one shared subject, which is $y$ ffermwr "the farmer". To solve the problems of the tense and subject, Sadler (2006) argues that coordination in this structure is between IP and VP and proposes the following phrase structure rule:

(29) IP

$$
\begin{gathered}
\text { IP } \\
\downarrow \epsilon \quad \uparrow \\
(\downarrow \text { TENSE })=(\uparrow \text { TENSE }) \\
(\downarrow \text { SUBJ })=(\uparrow \text { SUBJ })
\end{gathered}
$$

Conj

$\uparrow=\downarrow$

$$
\begin{gathered}
\mathrm{VP} \\
\downarrow \epsilon \quad \uparrow
\end{gathered}
$$

The annotations beneath the IP, which are $(\downarrow$ TENSE $)=(\uparrow$ TENSE $)$ and $(\downarrow$ SUBJ $)=(\uparrow$ SUBJ $)$, spread the feature of TENSE and SUBJ. The rule in (29) allows the following c-structure for the sentence in example (28): 


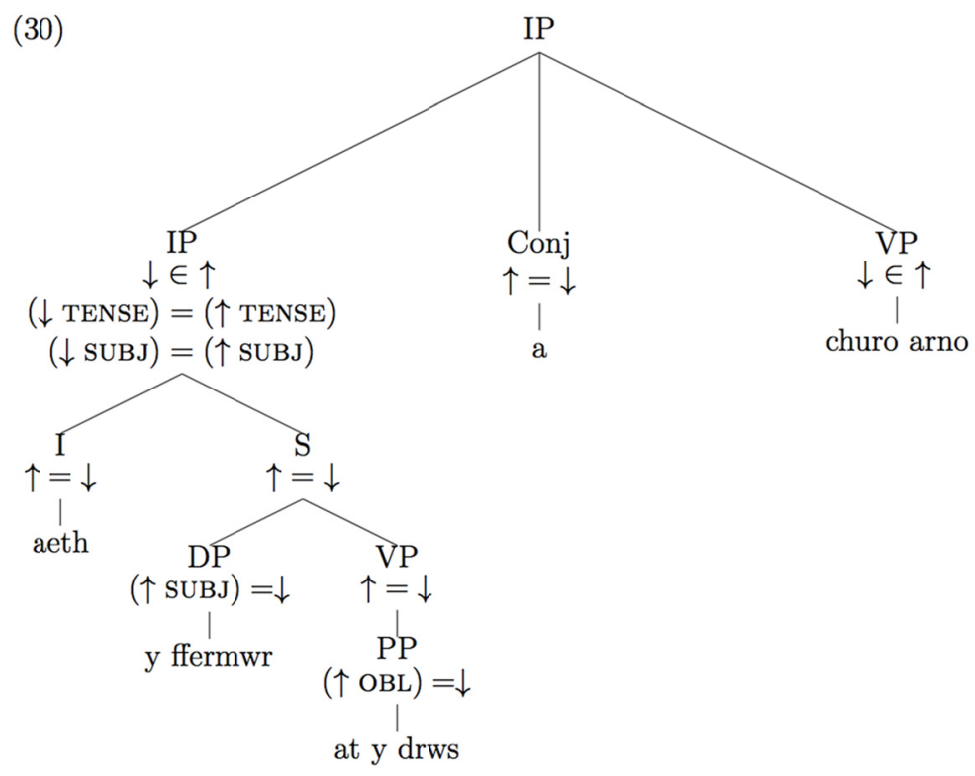

The f-structure in (31) shows the function information of this analysis. The SUBJ function and the TENSE feature, which are available in the first conjunct, are spread to the second conjunct. This spreading is represented in the f-structure by using the number 1 to connect the TENSE feature and the number 2 to connect the SUBJ feature between the two embedded f-structures.

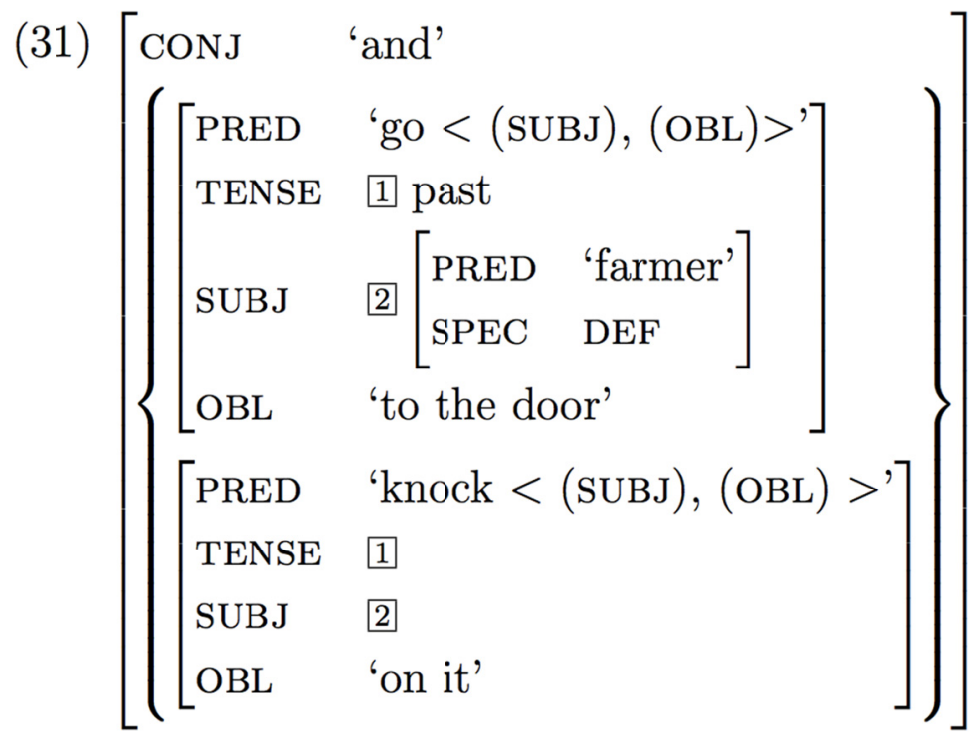

Alzaidi (2010) argues that the function spreading approach is the best approach for RNR in the Hijazi Arabic dialect. He proposes the following phrase structure rule and states that it allows for the spreading of the object function over the whole coordinate structure in this dialect.

(32) IP

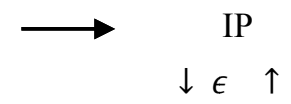

$$
\begin{aligned}
& \text { Conj } \\
& \uparrow=\downarrow
\end{aligned}
$$$$
\text { IP }
$$$$
\downarrow \epsilon \uparrow
$$$$
(\downarrow \text { OBJ })=(\uparrow \text { OBJ })
$$

The annotation $(\downarrow \mathrm{OBJ})=(\uparrow \mathrm{OBJ})$ beneath the IP node implies that the object of the second conjunct is spread over the whole construction and is shared by the two conjuncts in this way. In other words, this annotation 
implies that the OBJ is a distributive feature, and thus, the value of the OBJ is shared between the two clauses. Alzaidi $(2010,83)$ proposes the c-structure in (34a) and the f-structure in (34b) for the example in (33).

'Hind disproved and Khaled believed the news'

(34) a

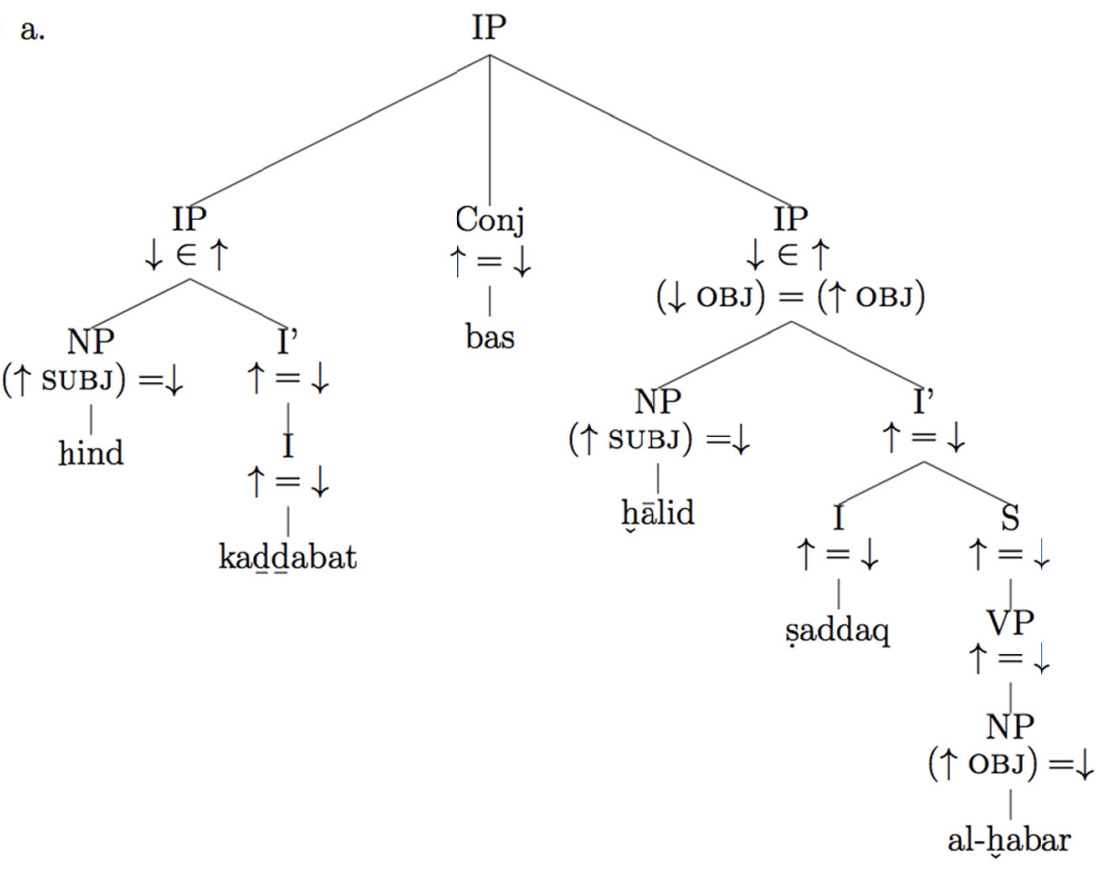

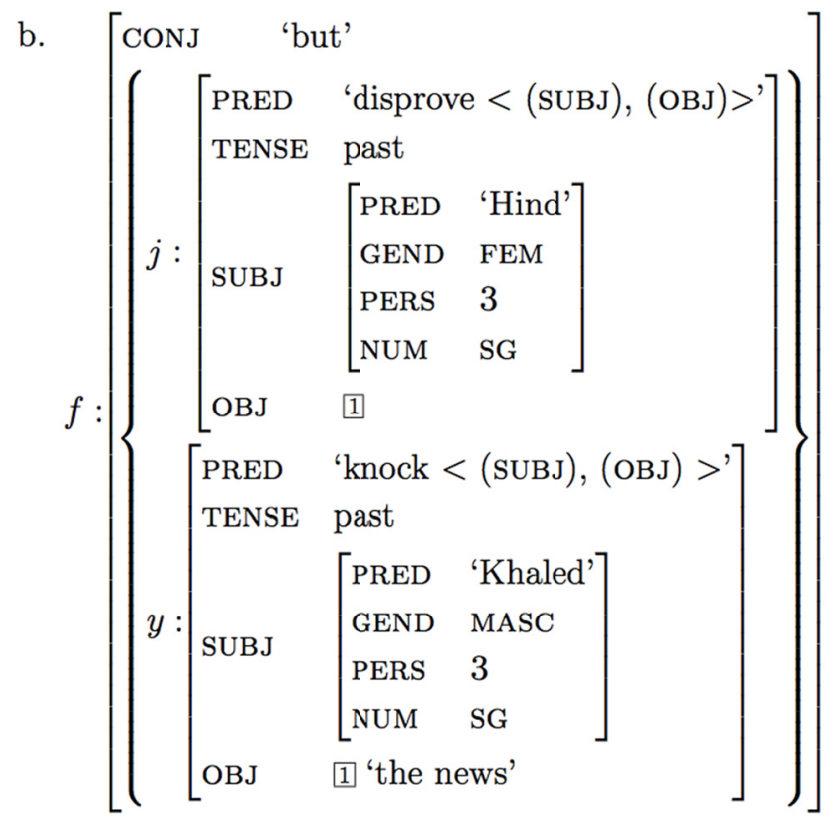

This analysis assumes that the coordinate structure is between two IPs and that both are members in a set shown in the f-structure. The f-structure labeled $j$ represents the first conjunct, and the predicate in this f-structure requires a SUBJ and OBJ. These requirements must be satisfied, or the f-structure will be ill-formed. The SUBJ function is available in this clause, and the OBJ is also available in this clause by sharing the value of the OBJ function with the second conjunct. The sharing relationship is represented by the number 1 shown in both clauses and can be represented by a line that connects the two functions in the twof-structures. 
This analysis may account for this phenomenon in the Hijazi Arabic dialect and can easily account for different positions of the pivot in MSA, as represented in examples (4a) and (5), repeated in (35) below.
a. $q \bar{a} b a l-t u$
wa kallam
sālim-un Raḥmad-a.
meet.PFV-1SG and talk.PFV-3SG Salem-NOM Ahmad-ACC
'I met (Ahmad) and Salem talked to Ahmad'
b. Pạ̣mad-a qābal-tu wa kallam Zayd-un. Ahmad-ACC meet.PFV-1SG and talk.PFV.3SG Zayd-NOM
'I met (Ahmad) and Zayd talked to Ahmad'

\author{
c. qābal-tu Pahmad-a wa kallam Zayd-un. \\ meet.PFV-1SG Ahmad-ACC and talk.PFv.3SG Zayd-NOM \\ 'I met (Ahmad) and Zayd talked to Ahmad'
}

A phrase structure rule such as that in (36) can successfully solve the problem of different positions in MSA by using a disjunction. In one case, the pivot occurs in the first conjunct, and in the other case, the pivot occurs in the second conjunct. Thus, the IP either with or without object spreading can occur in each conjunct.

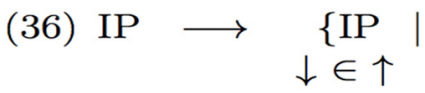
IP
$\downarrow \in \uparrow$
\} Conj $\{$ IP
$\uparrow=\downarrow \quad \downarrow \in \uparrow$
$(\downarrow \mathrm{OBJ})=(\uparrow \mathrm{OBJ})$
IP
$\downarrow \in \uparrow$
$(\downarrow \mathrm{OBJ})=(\uparrow \mathrm{OBJ})$

However, the case in MSA is more complicated, and the use of MSA reveals problems with this analysis. First, this approach cannot solve the problem caused by an example such as (21), repeated in (37). In this example, the shared element is al-manzil-i "the house", not the whole PP min al-manzil-i "from the house"; the first predicate requires an NP, which is al-manzil-i "the house", and the second predicate requires a PP, which is min al-manzil-i "from the house". The requirement of the second predicate (the PP) is available in the second conjunct, while the first predicate occurs without an overtobject.
(37) sālim-un dahala
wa ${ }^{c} a l \bar{\imath}-u n$ ȟară̆a
min al-manzil-i.
Salem-NOM enter.PFV-3SGM and Ali-NOM leave.PFV-3SGM from DEF-house-GEN
'Salem entered and Ali left the house'

Second, this analysis cannot account for an example such as (12), repeated in (38). This example contains two predicates sharing a single argument, which is Zayd, but the first predicate requires this NP as a subject, while the second requires it as an object. The NP carries an accusative case marking, making it suitable for the second predicate. This kind of example cannot be analyzed with a function spreading approach because it is assumed that the function that spread from the second clause is a general grammatical function (GF) using annotation such as $(\downarrow \mathrm{GF})=(\uparrow \mathrm{GF})$ beneath the second IP. The problem will remain in the f-structure, shown in (39). In this f-structure, the value of the OBJ attribute in $y$ f-structure is $h$ f-structure, and it contains an attribute called CASE with the value ACC, indicating that the case marking of this argument is accusative. This argument is thus unsuitable for the SUBJ function in $j$ f-structure, which needs a nominative case marking.

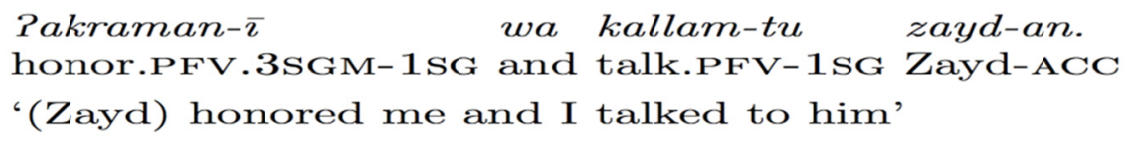




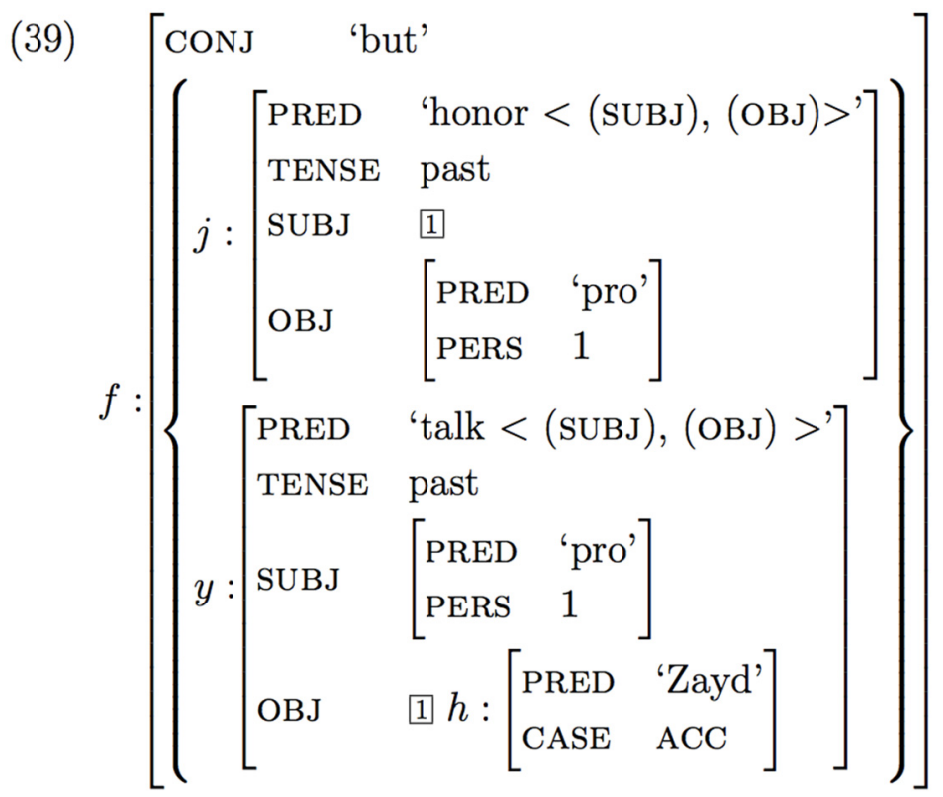

\section{MSA analysis}

This section proposes a new analysis in which missed arguments in each conjunct are analyzed as omitted arguments. This section demonstrates that this analysis is the best analysis for shared arguments in MSA and shows that it is possible in the LFG framework. This section opens with a short explanation of null subjects and objects in MSA and then demonstrates that the suggested analysis in this paper is able to account for all examples that caused serious problems for the previous analyses of this phenomenon in LFG.

\subsection{Null Subject and Object in MSA}

MSA is a pro-drop language, which means that a verb may occur without an overt subject if the subject can be understood. The null subject in this case can be understood from the agreement of the verb. The following examples illustrate null subjects in MSA:

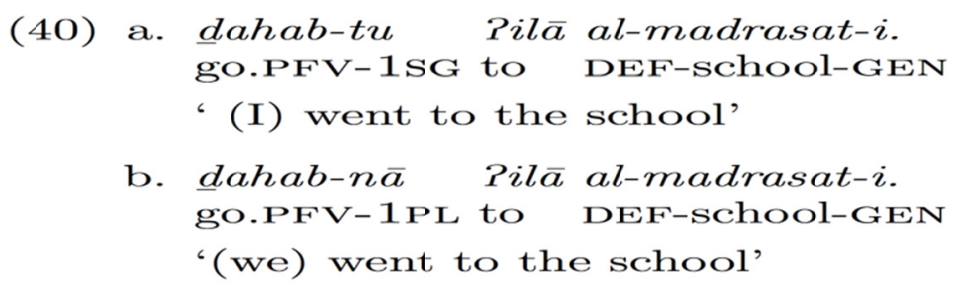

In example (40a), the verb $\underline{d} a h a b-t u$ "went" agrees with a first-person singular subject, and this agreement is understood from the suffix $t u$. The subject does not occur with the verb in this ex- ample. Similarly, the verb in example (40b) occurs with a null subject that is understood from the agreement of the verb. The verb $\underline{d} a h a b-n \bar{a}$ "went" agrees with a first-person plural subject by the suffix $n \bar{a}$. we assume that this suffix is only an agreement and it is not functioning as a subject as it is assumed in traditional grammar or other frameworks, including some LFG analyses.

Additionally, null arguments are not restricted to a subject function in MSA; other arguments, such as the object, can be omitted in MSA. In the following examples, the objects of the verbs are omitted. Both examples can occur in a context in which someone told the speaker something and the speaker replied with one of these examples. In example (41a), the verb fahim-tu "understood" forms a full sentence and is well-formed, indicating that this sentence is complete and contains all arguments required by the verb (a subject and an object) even though both are omitted because they can be understood from the context. Likewise, the verb 
sami ${ }^{c}-t u$ "I heard" in example (41b) lacks an explicit subject and object, although its requirements are satisfied. The following question thus arises: how can this kind of sentence be analyzed within a framework such as LFG?

(41)

a. fahim-tu.

understand.PFV-1SG

'(I) understood (it)'

b. $s a m i c-t u$.

hear.PFV-1SG

'(I) heard (you)'

In LFG, examples, such as the two examples in (41) are analyzed as containing null arguments. This paper will analyze them as having null arguments, but by using an empty category. This paper follows Simpson (1991) and Alotaibi (2014) in using an empty category in LFG. Simpson (1991) uses the empty category for analyzing auxiliaries in Warlpiri, while Alotaibi (2014) uses this category for analyzing the head noun of relative clauses in the Taif dialect. This paper claims that the following phrase structure rule that is proposed in Alotaibi (2014, p. 310) can be used here for the null subject or object.

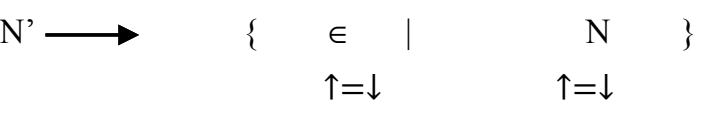

The rule in (42) covers two possibilities for a noun that functions as a subject or object, which are explicit or implicit. The symbol $\varepsilon$ in this rule corresponds to the empty category and allows the subject or object to be omitted. The first choice in this rule does not allow the omitted argument to appear in the c-structure and shows only that this element has a function in the f-structure. The following c-structure and f-structure represent the sentence in (41a), which lacks both an overt subject and an overt object.

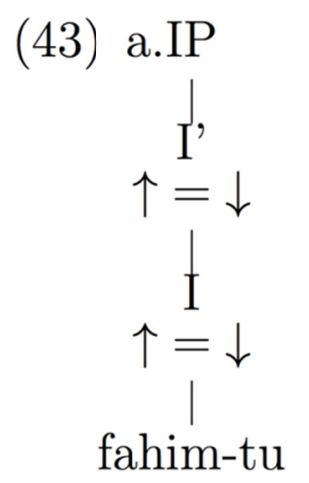




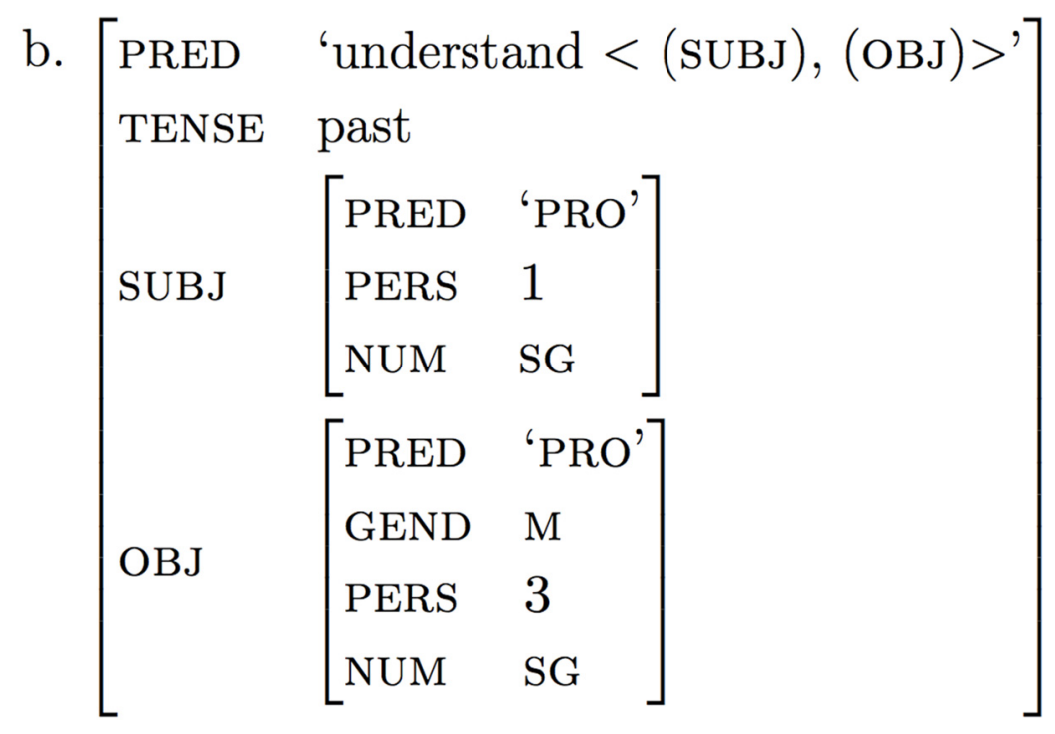

The f-structure in (43b) shows that the verb in this sentence requires a subject and object, and both requirements are satisfied. Therefore, this sentence is complete, and the f-structure is well-formed. The PRED of the omitted subject or object is represented as a PRED whose value is PRO, as shown in the f-structure in (43b).

\subsection{Suggested Analysis}

Verbs that contain null subjects and null objects in MSA can be coordinated. The following examples contain two conjuncts, each of which lacks an explicit subject and object.

$$
\begin{aligned}
& \text { a. sami } i^{c}-t u \quad w a \text { Patac }-t u . \\
& \text { hear.PFV-1SG and follow.PFV-1SG }
\end{aligned}
$$

'(I) heard (you) and followed (you)'

b. qaraP-ta wa katab-ta.

read.PFV-2SG and write.PFV-2SG

'(you) read (something) and (you) wrote (something)'

This paper suggests a new analysis for shared arguments in MSA, including RNR, and this analysis is based on the ability to omit the subject and object in MSA, as shown in previous examples. This paper suggests that the pivot element cannot be analyzed as a shared argument between the two conjuncts and should instead be analyzed as an argument that fills one function in its local clause. The missed argument in this case is assumed to be a null argument in MSA, where arguments can be frequently deleted, as demonstrated above. This analysis should be performed by adding a phrase structure rule such as that in (42), repeated below:

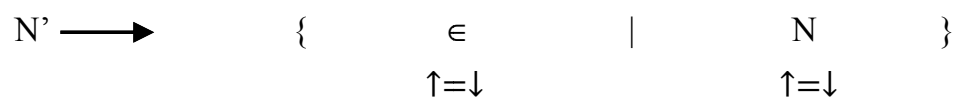

This rule allows nouns to be explicit or implicit in MSA. The following sentence, which illustrates RNR in MSA, has two conjuncts, and each verb in these conjuncts requires a subject and object, which is missing in the first conjunct. In the analysis proposed in this paper, we should assume that there is an omitted object in the first conjunct and that this omitted object is the same as the pronounced object in the second conjunct. The example in (46) will be represented in the c-structure in (47a) and the f-structure in (47b). The missing object in the first conjunct is not shown in the c-structure, but it is represented in the f-structure of the first conjunct, and the PRED of this object is "pro", as shown in the f-structure in (47b). 
(46) kataba

hālid-un wa qara?a

hāmid-un al-risālat-a.

write.PFV.3sGM Khaled-NOM and read.PFV.3SGM Hamed-NOM DEF-letter-ACC

'Khaled wrote and Hamed read the letter'

(47) a

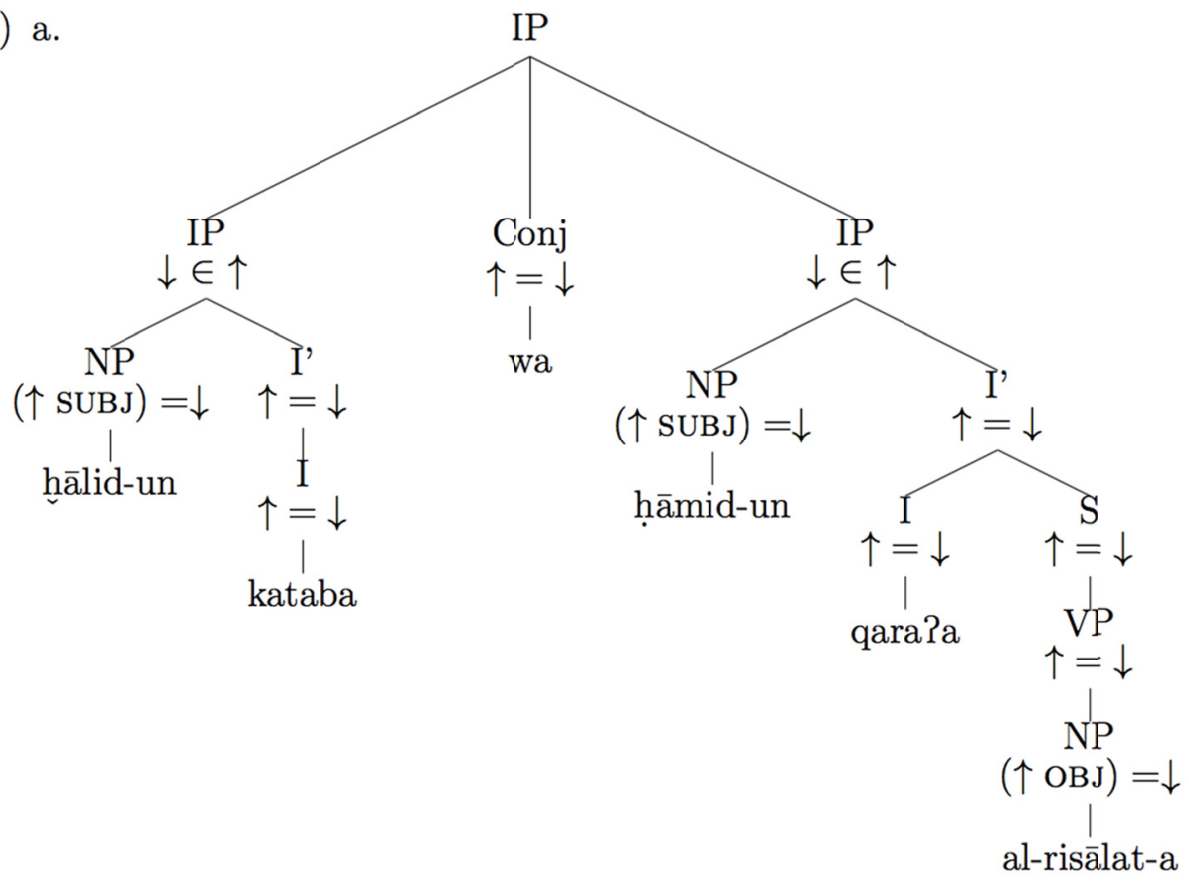

b.

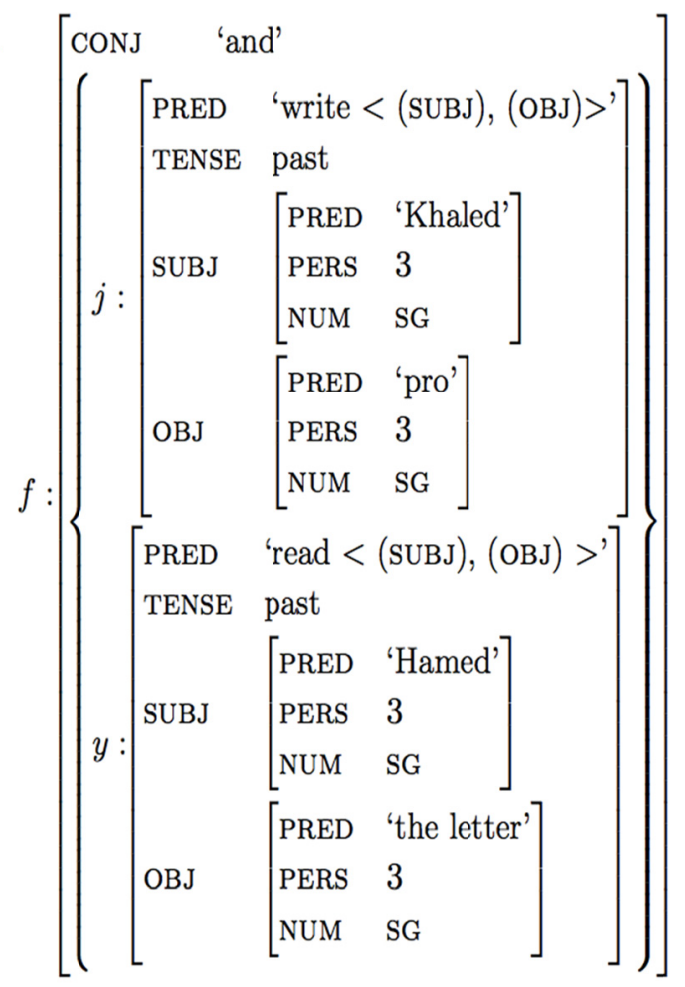

This analysis is easily able to account for RNR in MSA when the pivot appears in the second clause, as shown above, and this approach can also account for the shared object when it appears in the first conjunct, as shown in (5), repeated below as (48): 


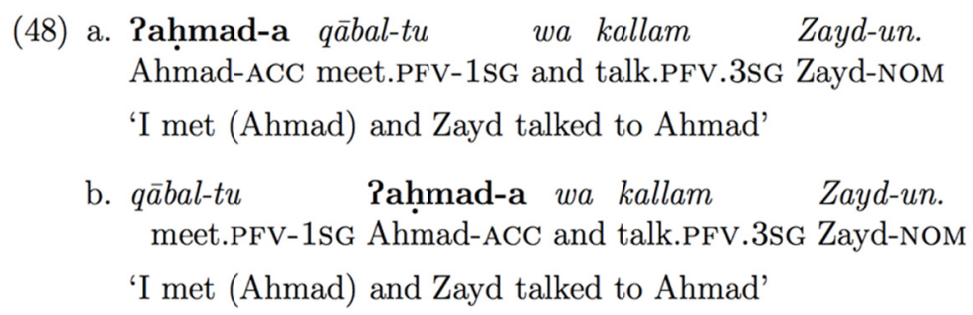

Additionally, the main advantage of this suggested analysis is that it can account for some examples in MSA that cannot be accounted for in other analyses. For example, an example such as (21), repeated as (49), contains a shared element that is needed for a different function in each conjunct. The NP al-manzil-i "the house" functions as an object of a preposition in the second conjunct, but it is needed to function as an object of the verb dahala "enter" in the first conjunct.

The analysis of this paper can solve this problem by assuming that an object is omitted in the first conjunct. The analysis of this example is represented in the c-structure in (50a) and the f-structure in (50b). Notably, the object of the verb in the first conjunct, which is not shown in the c-structure, is represented as "pro" in the f-structure in $(50 \mathrm{~b})$. The f-structure of the second conjunct clearly shows that the requirements of the two verbs differ, as the verb in the second conjunct requires an oblique, rather than an object, and this requirement is satisfied by the PP in the second conjunct. Thus, the connection between the value of OBL in the second conjunct and the value of OBJ in the first clause cannot make this f-structure well-formed. The feature CASE ACC in the OBJ f-structure in the first conjunct indicates that the "pro" fills a function that requires an accusative case marking. In contrast, the feature CASE GEN in the OBJ f-structure inside the OBL f-structure indicates that the NP "the house" fills a function with a genitive case marking.

(49) sālim-un dahala wa calī-un harağa mina al-manzil-i. Salem-NOM enter.PFV-3SGM and Ali-NOM leave.PFV-3SGM from DEF-house-GEN

'Salem entered and Ali left the house'

Another problem in MSA that cannot be solved by the previous LFG-based analyses of this phenomenon is shown in example (12), repeated in (51). In this example, the shared element zayd-an, which appears in the second conjunct, fills an object function in this conjunct, and the case marking of this noun is accusative. In contrast, the verb in the first conjunct requires the same proper noun as a subject, and the case marking of subjects in MSA is nominative, indicating that zayd-an cannot fill both functions with the accusative case marking. The suggested analysis in this paper can solve this problem by assuming that the missed element is a null subject. The c-structure in (52a) and f-structure in (52b) represent the coordinate structure in example (51). The verb in the first conjunct in this example requires a subject and an object. The subject is the proper noun Zayd, which appears in the second conjunct with an accusative case marking. Thus, we are led to assume that the subject of the verb in the first conjunct is pro, and it is represented in the f-structure only (the case marking of this pro is represented by the feature CASE NOM in the f-structure). Additionally, the verb in the first conjunct agrees with an object that is marked as first person and is represented in the f-structure as well. The verb in the second conjunct also requires a subject and an object. The subject is missing and is represented in the f-structure as pro, while the object is the shared element Zayd, which carries an accusative case marking (the case marking of Zayd is represented by the feature CASE ACC in the f-structure). In sum, the analysis of this paper can account for a shared element such as Zayd in this example, which is required to address a different function in each conjunct.

(51) Pakraman- $\bar{\imath} \quad$ wa kallam-tu zayd-an. honor.PFV.3SGM-1sG and talk.PFV-1SG Zayd-ACC

'(Zayd) honored me and I talked to him' 


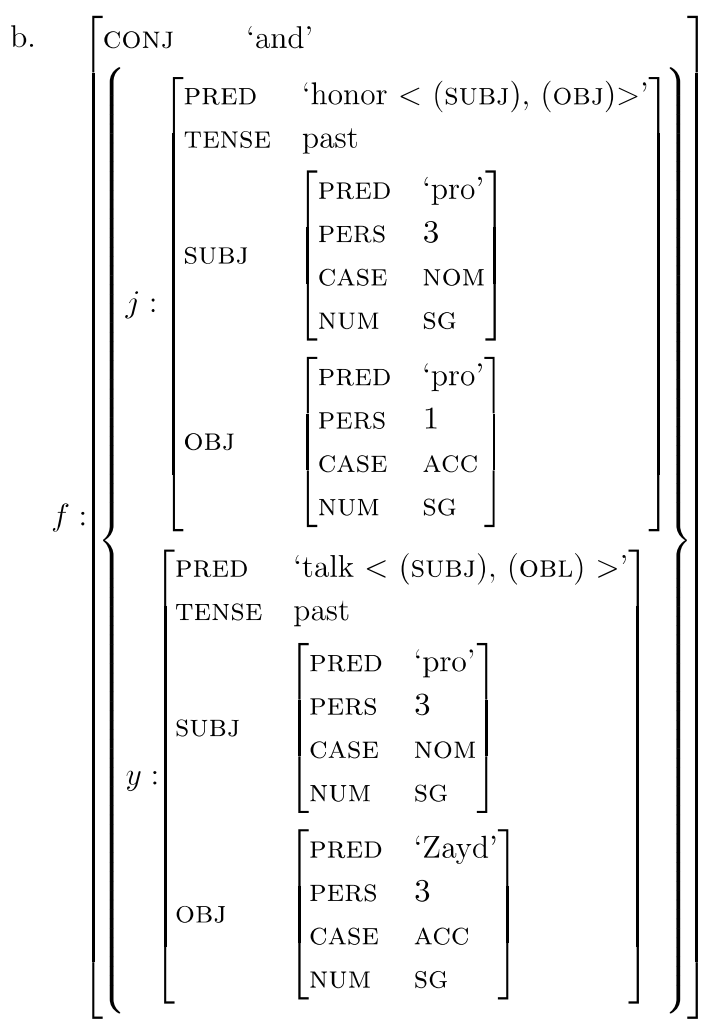

\section{Conclusion}

This paper has argued for a new analysis for shared arguments, including RNR, in the LFG framework. This work has shown that the previous analyses in LFG, namely, split analysis and function spreading, cannot account for all examples of this phenomenon in MSA. Therefore, this paper proposes a new analysis that can account for the two types of shared arguments in MSA discussed above and that can account for all types of examples for which problems arose for the previous LFG-based analyses. The new approach in this paper analyzes the missing argument as a null argument that should be presented in the f-structure as pro. This analysis, as shown above, can account for the shared argument when it fills a different function in each conjunct. Moreover, this analysis is consistent with the fact that MSA is a pro-drop language, which means that subjects and objects can be deleted. This paper suggests that the new analysis in LFG is applicable to other languages and can account for similar phenomena in other languages without problems.

\section{References}

Abbott, B. (1976). Right node raising as a test for constituenthood. Linguistic Inquiry, 7(4), 639-642.

Alotaibi, Y. H. (2014). Conditional Sentences in Modern Standard Arabic and the Taif Dialect. Ph. D. thesis, University of Essex.

Alzaidi, M. S. (2010). Gapping and right node raising: An LFG approach. Ph. D. thesis, MA Thesis. University of Essex.

Bresnan, J. (2001). Lexical Functional Syntax. Oxford: Blackwell.

Bresnan, J., Kaplan, R. M., \& Peterson, P. G. (1985). Coordination and the flow of information through phrase structure. MS, Xerox PARC.

Chomsky, N. (1986). Barriers. Cambridge, MA: The MIT Press.

Dalrymple, M. (2001). Lexical Functional Grammar, 42. New York: Academic Press. https://doi.org/10.1163/9781849500104

Duman, B., \& van Riemsdijk, H. (2003). Right Node Raising \& Turkish. Ph. D. thesis.

Frank, A. (2002). A (discourse) functional analysis of asymmetric coordination. In M. Butt \& T. H. King (Eds.), 
Proceedings of the LFG02 Conference. Stanford, CA. CSLI Publications. Retrieved from $\mathrm{http}: / / \mathrm{www}-\mathrm{csli}$.stanford.edu/publications

Ha, S. (2008). Ellipsis, right node raising, and across-the-board constructions. ProQuest.

Hartmann, K. (2000). Right node raising and gapping: Interface conditions on prosodic deletion. Amsterdam: John Benjamins Publishing.

Jackendoff, R. S. (1977). X-Syntax: A Study of Phrase Structure. Cambridge, MA: MIT Press.

Kaplan, R. M., \& Bresnan, J. (1982). Lexical-Functional Grammar: A formal system for grammat- ical representation. In J. Bresnan (Ed.), The Mental Representation of Grammatical Relations (pp. 173-281). Cambridge, MA: The MIT Press.

Kaplan, R. M., \& Maxwell, III J. T. (1988). Constituent coordination in Lexical-Functional Gram- mar. In Proceedings of the 12th International Conference on Computational Linguistics (COL- ING 88), 1, Budapest, pp. 303-305.

Maxwell, J. T., \& Manning, C. D. (1996). A theory of non-constituent coordination based on finite-state rules. In Proceedings of $L F G, 96$.

Postal, P. M. (1974). On raising: One rule ofenglish grammar and its theoretical implications.

Ross, J. R. (1967). Constraints on variables in syntax. Ph. D. thesis, MIT.

Rouveret, A. (1994). Syntaxe du gallois. Paris, France: Editions CNRS.

Ryding, K. (2005). A reference grammar of modern standard Arabic. Cambridge Univ Pr. https://doi.org/10.1017/CBO9780511486975

Sabbagh, J. (2007). Ordering and linearizing rightward movement. Natural Language \& Linguistic Theory, 25(2), 349-401. https://doi.org/10.1007/s11049-006-9011-8

Sadler, L. (2006). Function spreading in coordinate structures. Lingua, 116(11), 1777-1806. https://doi.org/10.1016/j.lingua.2004.09.005

Shabani, M. (2015). Right node raising: A nonhomogeneous construction in persian. Language Related Research, $6(2)$.

Simpson, J. (1991). Warlpiri Morpho-Syntax: A Lexicalist Approach. Dordrecht: Kluwer Academic Publishers. https://doi.org/10.1007/978-94-011-3204-6

Wilder, C. (1999). Right node raising and the lca. In Proceedings of WCCFL, 18, pp. 586-598. Somerville, MA: Cascadilla Press.

Wyngaerd, G. (2009). Gapping constituents: a revised version of 1998 version. Ms., FWO/KU Brussel.

\section{Notes}

Note 1. The paper uses the following abbreviation in the glossing: PFV: PERFECTIVE, IPFV: IMPERFECTIVE, DEF: DEFINITE, 3SGM: THIRD PERSON, SINGULAR AND MASCULINE, NOM: NOMINATIVE, ACC: ACCUSATIVE, GEN: GENITIVE, IMP: IMPERATIVE, JUSS: JUSSIVE, FUT: FUTURE, PASS: PASSIVE, ACT: ACTIVE, PTCP: PARTICIPLE.

Note 2. The data in this paper were obtained from experts in Arabic linguistics departments in some universities in Saudi Arabia, including the author, who has knowledge about this language.

Note 3. The clause is complete if it contains all the governable grammatical functions that are required by its predicate (see Dalrymple, 2001).

\section{Copyrights}

Copyright for this article is retained by the author(s), with first publication rights granted to the journal.

This is an open-access article distributed under the terms and conditions of the Creative Commons Attribution license (http://creativecommons.org/licenses/by/4.0/). 